\title{
ГЕНДЕРНОЕ (НЕ)РАВЕНСТВО В ДЕТСКОМ САДУ: МАТЕРИНСКИЕ НАРРАТИВЫ О СКРЫТОМ УЧЕБНОМ ПЛАНЕ И ДЕВИЧЕЙ ИДЕНТИЧНОСТИ
}

В статье актуализируется значимость изучения дошкольного девичества как особой культуры, в рамках которой формируется гендерная идентичность дошкольницы. Изучение этого процесса проведено на примере анализа материнской рефлексии дошкольного образования девочек в детском саду. Основной исследовательский вопрос направлен на реконструкцию имплицитных, заложенных в «скрытом учебном плане» практик, формирующих девичью идентичность через принятые и навязываемые обществом нормы женственности посредством анализа материнского восприятия практик детского сада. Эмпирическая база исследования - 11 индивидуальных интервью с матерями девочек-дошкольниц и четыре «диадных» интервью с матерями и их дочками 4-7 лет, собранные в 2016 г. Анализ материнского описания различных видов деятельности в детском саду показывает, что «скрытый учебный план», конструирующий девичью идентичность, пронизывает весь распорядок дня дошкольниц: выбор образовательной траектории, сюжетно-ролевую игру, прогулку, сон, одежду и внешний вид, праздники. Анализ собранных интервью показал, что матери поддерживают гендерные элементы воспитания ребенка в детском саду, выдвигая свои аргументы согласия и обоснования принятых в детском саду воспитательных практик. В партнерстве с детским садом формируют скрытый учебный план, навязывающий девочке традиционную модель женственности, создают практики социализации, задающие рамки конструирования девичей гендерной идентичности, лишая возможности индивидуальной образовательной траектории и формирования неповторимой

Анастасия Алексеевна Чередеева - магистрантка Факультета социальных наук НИУ ВШЭ, г. Москва, Россия. Электронная почта: cheredeeva.a@gmail.com

Ольга Борисовна Савинская - к.соц.н., доцент Факультета социальных наук НИУ ВШЭ, г. Москва, Россия. Электронная почта: osavinskaya@hse.ru 
личности. Гендеризованный скрытый учебный план оказывается действенным механизмом формирования дошкольного девичества и стартовых рамок дальнейшей гендерной социализации в школе. Детский сад не только готовит девочку к обучению в школе, он учит ее быть «девочкой» в школьные годы, усваивать предлагаемые обществом нормы, предписанные школьному возрасту.

Ключевые слова: девочки-дошкольницы, гендерная идентичность, скрытый учебный план, материнство, гендерная экспертиза дошкольного образования

DOI: 10.17323/727-0634-2018-16-3-441-456

Социальный мир девочек-дошкольниц как исследовательский фокус достаточно нов, а интерес к проблемам социализации девочек, конструированию их гендерной идентичности и изучению девичества как особой гендерной культуры активизируется. Это направление развивается на стыке двух областей - социологии детства, признающей этот этап жизни как самодостаточный и формирующий особый социальный мир смыслов и культурных образцов (Майорова-Щеглова 2014), и гендерной социологии, изучающей образцы женственности и мужественности разных возрастных групп как важную составляющую гендерной культуры общества (Бем 2004) и их встроенность в программы дошкольного образования (Штылева 2001).

Дошкольное образование - это ключевой социальный институт, не только формирующий познавательные и коммуникативные навыки ребенка (Heckman 2006), но и влияющий на социализацию в целом. В дошкольном возрасте происходит первая половая самоидентификация, принятие гендерных ролей и образцов взаимодействия. Гендерная самоидентификация в детском саду конструируется через включение в практики совместного обучения, игры, выполнение действий по самообслуживанию, уходу за собой. Освоение и интернализация гендерных различий - важнейший аспект социализации.

Дошкольное образование долгое время воспринималось достаточно узко, как профессиональная деятельность педагогов, направленная на обучение и воспитание вверенных им детей. В настоящее время образование понимается как социально ответственная деятельность, в которой родители становятся одними из влиятельных субъектов (Майофис, Кукулин 2010; Асонова 2010), имеющих свою точку зрения на развитие дошкольного образования в целом и отдельных его аспектов. Вовлеченные родители, чаще всего матери, оказываются внимательными участниками и наблюдателями образовательного процесса (Савинская 2015), соединяющими правила домашнего поведения и жизни ребенка в детском саду. Исследования также показывают, что для ребенка старше трех лет среди членов семьи лидером по количеству проведенного вместе времени является мать, а институт материнства играет одну из ключевых ролей в жизни дошкольника (Гурко 2008: 197; Савинская 2014). 
Базируясь на этих данных, в исследовании предпринята попытка изучить материнский взгляд на процессы гендерной социализации и формирование девичей идентичности в детском саду. Мы поставили перед собой исследовательские вопросы о том, как именно матери девочек дошкольного возраста воспринимают и оценивают ежедневные практики и образовательные программы дошкольных образовательных учреждений. Видят ли они в этом аспекты гендерного воспитания, и как они к этому относятся? Как этот эмпирический материал позволяет описать гендерную социализацию девочек в детском саду? В статье мы реконструируем через материнское восприятие имплицитные практики детского сада, заложенные в «скрытом учебном плане» (Jackson 1968; Штылева 2001; ЯрскаяСмирнова 2001) и формирующие девичью идентичность через принятые и навязываемые обществом нормы женственности.

\section{Методология и методы}

Для решения поставленных вопросов нами было проведено качественное исследование, направленное на изучение гендеризованных практик в детских садах, транслируемых через призму рассказов матерей о воспитании и «научении» дочерей взаимодействовать и вести себя в разных ситуациях. Наше исследование носило разведывательный характер, поскольку количественных гендерных исследований о практиках детского сада в России не проводилось, а также исходя из того, что институты детства и образования сегодня претерпевают колоссальную трансформацию, связанную как с развитием технологий, так и с «переоценкой» советских ценностей. Эмпирической базой стали 11 полуформализованных индивидуальных интервью с матерями и четыре интервью в диадах (дочь 4-7 лет и мать). Несмотря на то что интервьюерами предпринимались попытки вовлечь детей в разговор, дети мало участвовали, и диадные интервью в основном оставались материнским нарративом. Полевой этап исследования проходил в апреле и мае 2016 г. Возраст информанток-матерей - от 27 до 40 лет; на момент проведения интервью оценили свой достаток как средний или выше среднего. Все дети посещали государственные/муниципальные детские сады. Десять матерей работали, но их доход не являлся основным для их семей. Среди опрошенных не оказалось мигрантов из других стран, переезд в Москву из другого города ни в одном интервью не артикулирован. В рамках анализа данных уделялось также внимание условиям сбора данных (Lofland, Lofland 1995): интервью проводились в спокойной обстановке дома у информанток.

Исходя из особенностей организации времени и пространства в муниципальных детских садах в России, мы выбрали для изучения такие виды активностей, как послеобеденный сон, групповая прогулка, детские праздничные утренники, занятия физкультурой, занятия танцами. Эти категории 
выделены исследователями образовательного пространства детского сада и заданы как определяющие его с точки зрения родительской оценки (Савинская 2015). Все они, будучи организованны в стенах детского сада, отличаются от подобных практик, выполняемых дома. Они включают самостоятельное взаимодействие со сверстниками и с воспитателем как значимым взрослым, помещены в определенный контекст дошкольного учреждения.

\section{Образование как институт детства и гендерная идентичность}

Институты детства претерпевают значительную трансформацию. Теоретические и эмпирические исследования показывают, что родительство, детство и процесс первичной социализации заметно трансформируются: то, что было нормой несколько десятилетий назад, уже устаревает. Так, Майорова-Щеглова (2014) выделяет несколько факторов, влияющих на социальные изменения в институтах детства. Среди них новое отношение к репродукции человека и технологии его осуществления, расширение и принятие идеи прав ребенка и рост потребительского рынка детских товаров и услуг.

Феномен гендерной социализации ярко описан Сандрой Бем (2004). Она подробно раскрывает социокультурный аспект полоролевого поведения, приписанных обществом норм поведения. Они становятся своего рода социокультурными «линзами», которые транслируют устоявшиеся в обществе правила поведения и личностные качества, свойственные мужчинам и женщинам - линзу андроцентризма, полярность или дихотомичность «мужского» и «женского», биологичность «мужественности» и «женственности». Концепция гендерных линз согласуется с понятием «гендерного дисплея» Ирвинга Гофмана (Goffman 1976), также адресующего к нормативным социальным ожиданиям и их исполнению. Гендерный дисплей помогает идентифицировать участников коммуникации как носителей пола, что делает процесс коммуникации более определенным.

В российской социологии Е.Р. Ярская-Смирнова (2001) одной из первых начала дискуссию о влиянии гендерных стереотипов на складывающиеся образовательные практики. Являясь одним из самых важных институтов социализации, образование в числе своих функций имеет трансляцию жизненных ценностей и ориентиров, передачу опыта и знаний от поколения к поколению и помощь в самореализации и самоидентификации личности. Таким образом, образование, как и семья,- агент первичной социализации, закладывая базовые нормы, ценности и роли, в том числе и касающиеся гендерной идентификации аккумулируется в понятии «скрытый учебный план» (Jackson 1968). Филип Джексон видел в этом феномене самые разные аспекты социализации учеников, не отраженные в учебном плане, но с неизбежностью реализуемые его выполнением. В рамках нашего исследования, мы фокусируемся на его гендерной составляющей (Ярская-Смирнова 2001): формирование 
гендерных стереотипов и, как следствие, установок, касающихся пола у воспитанников детских садов.

Понятие идентичности обычно связывают с именем Эрика Эриксона (1996). Под идентичностью мы понимаем формирование в процессе жизнедеятельности жизненного опыта и собственного образа Я. Идентичность определяется рамками социальных институтов. Гендерная идентичность основа идентичности человека. Джудит Лорбер полагает ее как «осознание себя как представителя данного пола, ощущение своего женского или мужского тела, осознание своей принадлежности к полу в социальном контексте» (Лорбер 1994: 132). Гендерная идентичность является осознанным формированием позиции Я по отношению к нормативно заданным свойствам пола или соответствие заданными «эталонным» нормам поведения мужчин или женщин. Проведенные на основе теоретических подходов исследования показывают, что идентичность в разных возрастах конструируется особенным образом, и что процесс этот отнюдь не сводится к воспроизведению усвоенных норм, но и к их постоянному конструированию (James et al. 1998; Schmidt, Tomasello 2012). В дошкольном возрасте наполненность компонентов идентичности малоизучена, что дает пространство для новых исследований того, какие именно гендерно-обусловленные практики свойственны детям в детских садах.

Виктория Перегудина (2013: 185) комплексно рассматривая когнитивный, аффективный, поведенческий и семантико-символический аспекты формирования идентичности в дошкольном возрасте, отмечает, что наиболее наполненной является аффективная составляющая, показывающая отношение к своей гендерной идентичности и ее принятие. Дети в дошкольном возрасте слабо осознают когнитивные компоненты гендера. Они выделяют, как правило, наиболее яркие атрибуты (мальчики - грубые, драчливые, девочки - нежные, добрые). При описании гендерных характеристик своего Я, дошкольники больше ориентируются на внешний вид. Так же результаты исследования показывают, что восприятие пола у дошкольников высоко стереотипизировано и нормативно задано. Представления о гендерных ролях и умениях слабо сформированы и осознаваемы. Поведенческая составляющая, в основе которой лежит использование в модели поведения гендерно-окрашенных практик, сформирована слабее всего. Это может объясняться отсутствием жизненного опыта и низким уровнем осознаваемости компонентов гендерной идентичности. Процесс гендерной социализации должен учитывать уникальность ребенка, чтобы гендерное образование не превращалось в «псевдо-гендерное», сужающее символические, ролевые и мотивационные аспекты развития ребенка (Гусева 2016).

Сегодня исследователи отмечают изменяющиеся практики родительства (Reay 1998). С одной стороны, родители все более вовлечены в конструирование индивидуальной траектории ребенка: матери все больше участвуют в процессе планирования и реализации ускоренного развития 
ребенка (Старостина 2017), что получило название «интенсивного материнства». С другой стороны, родители вовлекаются в решение общественных проблем образования. Роль государства в дошкольном образовании ослабевает, формируются новые модели партнерства государственных организаций с родительской общественностью. Однако административное давление на институт дошкольного образования, усиление бюрократизации образовательных учреждений консервирует старые образцы и тормозит развитие партнерских отношений между родителями и воспитателями как представителями института образования. Это снижает и уровень критичности во взглядах родителей: конформное поведение родителей оказывается востребованным и удобным.

\section{Результаты исследования}

Развивая концепцию «скрытого учебного плана» в дошкольном образовании (Савинская 2016), мы утверждаем, что он включает в себя разные педагогические практики обучения, а также практики ухода и присмотра, что не менее важно для понимания целостности образовательного процесса в дошкольном учреждении. Анализ собранных интервью показал, что матери поддерживают гендерные элементы воспитания ребенка, выдвигая свои аргументы и обоснования принятых в детском саду воспитательных практик. В партнерстве с детским садом они формируют гендеризованный «скрытый учебный план» или образовательные практики, которые не вписаны в образовательные программы, но подспудно транслируются в ходе их реализации. Он навязывает девочке традиционную модель женственности, создает правила социализации, которые задают узкие рамки конструирования девичей идентичности, лишая возможности индивидуальной образовательной траектории и формирования своей неповторимой личности.

\section{Оценка образовательной программы}

Нами было выявлено, что матери понятие «образовательная программа» в детском саду скорее связывают с творческим развитием дочери, а не с получением знаний и умений, таких как письмо или счет. Апеллируя к развитию ребенка в ходе реализации образовательной программы, высказывания матерей, тем не менее указывает что выбор занятий предопределяется гендерными стереотипами:

У нас там и уроки рисования, и музыкальные занятия, потом на этих музыкальных занятиях у них готовятся программы к праздникам... К осенним праздникам, потом к 23 февраля, 8 марта, разучивают песни, разучивают стихи, потом какого-то типа представления. Мы делаем дома костюм, который нужен <..> В принципе менять бы программу я не стала, там дают всякого понемногу, но мы все равно ходим дополнительно на танцы, <..> потому что хотим, чтобы [Имя] более профессионально занималась танцами (Инт. 1, 28 лет). 
Разговор о развитии творческих навыков эмоционально окрашивается, матери подчеркивают их субъективную значимость для успешного взросления дочери. Отмечают «любовь» своих дочерей к танцам и музыке, которую поощряют, даже если иногда эти занятия не нравятся девочкам:

Мы очень рады, что она не сопротивляется ходить на музыкальные занятия. Она очень спокойный ребенок, и делает все, что ей скажут [Смеется]. Так что вроде бы ее сильно не воротит от этих занятий. Но мы с папой очень бы хотели, чтобы она занималась музыкой профессионально в будущем (Инт. 9, 36 лет).

Интервью показывают, что матери отдают девочек на эти занятия, предполагая, что это обязательный аспект девичьего дошкольного образования. Для них важно, чтобы их дочери занимались танцами и музыкой, несмотря на желания самого ребенка. Матери предписывают детям «природную» предрасположенность к творческим видам деятельности, закрепляя гендерный стереотип об артистических видах деятельности как наиболее подходящих для девочек.

\section{Прогулка и свободная игра}

Групповая прогулка в пределах территории дошкольного учреждения - ежедневная практика. Дети гуляют в большинстве случаев два раза в день. Прогулки осуществляются под контролем воспитателей, однако предполагают добровольные спонтанные детские игры и взаимодействия. Игры, которыми заняты дети во время прогулок, имеют разную направленность, которая также характеризуется гендерной окрашенностью. Мальчики и девочки играют в разные игры. Об этом говорили все матери, также как и включенные в разговор девочки в диадных интервью. Роль девичей свободной игры часто варьируется в рамках широко известной игры «дочки-матери». Она направлена на конструирование и воспроизведение моделей семьи и моделирования семейных ролевых взаимодействий между матерью и дочерью, реже - между супругами. Как правило, в этих играх принимают участие только девочки. Однако среди информанток была мать, чья дочь играла в семью с двумя мальчиками. Она всегда играла роль матери, а мальчики, меняясь, выполняли роли папы или сына:

Да, есть у нее два друга. Эта троица частенько играет в семейку... [Имя] всегда за маму. Ухаживает за ребятами, готовит им в песочнице куличики, пирожки. А мальчик обычно будто бы с работы приходит [Смеется], [Имя] его встречает и кормит (Инт. 5, 28 лет).

Однако эта история появилась только в одном интервью. В остальных сообщалось о том, что девочки играют в семью друг с другом, воображая себя матерью и дочерью. Эти игры подкрепляют стереотипные представления 
о предназначении женщины как матери и о моделях поведения в семье. Встречались также реплики о том, что воспитатели стараются учить детей играть вместе, однако, такие попытки, как правило не перерастают в общую «традицию». Девочки играют по отдельности, и при этом мамы реагируют спокойно, считая, что так и должно быть, ведь мальчики и девочки имеют разные интересы.

\section{Свободная сюжетно-ролевая игра как подготовка к выбору профессии}

По оценкам матерей, их дочери характеризуются схожестью в выборе любимых профессий для сюжетно-ролевых игр в детском саду. В качестве желаемых среди девочек 4-7 лет упоминались профессии ветеринара и воспитательницы.

Рассмотрим профессию ветеринара, как карьерную перспективу девочки дошкольного возраста. Увлеченность девочек этой профессией, на наш взгляд, в момент сбора данных была усилена популярностью мультипликационного сериала «Доктор Плюшева». Матери отмечали, что проигрывание роли ветеринара учит дочерей заботе и любви к окружающим. Они наделяют этими качествами некий идеальный образ женщины, к которому должна стремиться дочь. Сюжетно-ролевые игры в дочки-матери со сверстницами и даже игры с мягкими игрушками превращаются в своеобразную обучающую практику заботы и ухода о ком-то. Матери поощряют такое поведение, укореняя в дочери представления о том, чем должна заниматься женщина и какими житейскими умениями обладать:

Мне кажется, что профессия ветеринара очень жизнеутверждающая, потому что самое главное в этой профессии, как мне кажется, это любовь к живому существу... Эта профессия очень добрых людей... Мне кажется профессия накладывает свой отпечаток. Все-таки для девочки очень важно быть мягкой, доброй, заботливой. Она обязательно должна стремиться к этому... Я учу ее тому, что в будущем ей обязательно нужно будет заботиться о своих детишках, а как же без этого (Инт. 6, 27 лет).

По мнению матерей, профессия ветеринара воспринимается девочками как сфера деятельности, в которой они смогут реализовать свои природные задатки и качества, такие как забота о слабом существе. Иными словами, девочки в этом возрасте уже имеют склонность к проявлению материнских привязанностей, которые во многом навязаны стереотипным пониманием женских профессий и жизненных стратегий.

\section{Образ воспитательницы}

Воспитатель часто является одним из «ключевых взрослых» для ребенка, воспринимаемый девочками как социальный ориентир. В нашей выборке на нашлось информанток, воспитателями в детских садах которых были бы мужчины. Эта профессия является очень феминизированной. С воспита- 
тельницами дети проводят практически все время пребывания в детском саду. Как показывает анализ интервью, они не только являются формальными лидерами группы, которые имеют отчасти принудительную силу, но так же являются образцом для подражания. Для девочек это особенно важно, поскольку практически наравне с матерью в их жизни появляется женщина, которая транслирует нормы женственности. Это выражается как в поведении воспитательницы, так и вещах, которым она учит детей:

И: А есть ли что-то чему учит [Имя] вне учебной программы?

Р: Конечно... Она учить детей вести себя друг с другом... Учит, что девочка должна быть всегда чистой и красивой, что мальчики должны девочек защищать и приглядывать за ними (Инт. 13, 39 лет).

Матери оценивают воспитательниц в детских садах как своих «коллег» по воспитанию детей, то есть они осознают функцию педагога как проводника норм поведения для ребенка. Указания на то, что с воспитательницами у детей или родителей возникают конфликты, в интервью мы не получили. Наоборот, чаще всего матери выражали конформное согласие с деятельностью воспитателя, нежели ее критическое осмысление.

\section{Послеобеденный сон}

Часть материнских рассказов, вызвавших наше исследовательское удивление, - это обоснование правил послеобеденного сна в детском саду. В наших интервью проявилось мнение матерей о том, что девочки и мальчики должны взаимодействовать сообща как носители разных, непохожих идентичностей во время прогулок, игр и творческих занятий. Иными словами, матери допускают и поощряют гендерно-распределенные ролевые модели в различных ситуациях взаимодействия. Тем не менее, когда речь заходит о практике послеобеденного сна в детском саду, родители отрицают необходимость разделять помещения, в которых спят дети или же каким-то другим способом разделять их практики ухода:

Потому что, мне кажется, нет еще такого четкого разделения на мальчиков и девочек. Они все садовские дети. <... у них еще нет такого интереса. <..> Идет только знакомство с противоположным полом, но без акцента на половые признаки (Инт. 11, 35 лет).

Таким образом, матери отрицают телесные проявления мужского и женского в детских садах, они уверены, что дети в таком возрасте существа, в какой-то степени «бесполые». Этот тезис противоречит тому, что мы выявили ранее. Матери, обучая своих детей с детства тому, что мальчики и девочки являются противоположными, в ситуации проявлений телесности заявляют, что дети пока не осознают телесных различий между мальчиками и девочками. Получается, что матери уверены, что в дошкольном возрасте гендер проявляется не как биологически определённый 
признак пола, а в самом чистом социальном виде, то есть через практики поведения и взаимодействия с окружающими, а также через усвоение полоролевых ожиданий и их оправдания.

\section{Предпочтения в цветах}

В детских садах гофмановский «гендерный дисплей» начинается с цветовой идентификации девичей одежды. Рынок детских товаров сегодня характеризуется четким гендерным разделением вещей, как по цвету, так и по функциям. Розовый цвет с самого рождения человека символизирует женственность. В первые дни жизни, при выписке из роддома новорожденных девочек укутывают в розовые «конверты». Таким образом, ребенку, который только вошел в этот мир, уже приписывают гендерно-ориентированные атрибуты. Любовь девочки дошкольного возраста к розовому цвету может быть обусловлена более ранними практиками. Исследования показывают, что осознание идентичности в этом возрасте носит нормативный характер. Девочка «учится» носить розовые вещи, поскольку общество диктует, что именно эти цвета ассоциируются с женским образом, критерии соответствия гендерному дисплею соблюдаются:

Самый любимый цвет у нас - это розовый... Как и все девочки, она очень любит наряжаться, платья старшей таскает и мамины туфли [Смеется]. Вы знаете... старшая тоже так делала, когда была ее возраста. Да и мне мама моя рассказывала, что я очень любила носить ее вещи в свое время < .. >. А я и не против того, что мелкая из себя воображает, пусть знает, что носить потом будет (Инт. 234 года).

В своих репликах матери транслируют не только поддержку цветовых предпочтений, но и практики ношения одежды и девичьи игры с переодеванием как свойственные только девочкам.

\section{Праздничные утренники}

В детских садах праздники устраивают ежегодно по официальным случаям. Через повторяющееся каждый год торжественное мероприятие ребенок усваивает «праздничность» того или иного повода, а также приобщается к культуре общества и принятым нормам. Атмосфера праздника формирует у ребенка признание важности отмечаемого события. Так, гендерно-окрашенные утренники (в честь 8 марта и 23 февраля) закладывают в детях понятия о полоролевых различиях идентичности. Конструирование праздника также делает свой вклад в гендеризованный «скрытый учебный план». Определение концепции праздника и распределение ролей между его участниками носит стереотипный характер и выдает «ожидаемые» от детей того или иного пола образы как одобряемые. Распределение ролей лежит на воспитателе в детском саду и часто мнения детей о том, кого бы они хотели сыграть или в каком образе предстать перед зрителями, не спрашивается. Девочкам, по рассказам матерей, обычно достаются 
феминные роли, такие как снежинка, принцесса, ягодка, а мальчикам маскулинные: волк, медведь, гном и другие.

\section{Дискуссия}

Описание предложенных выше видов организованной деятельности в детском саду показывает, что гендеризация «скрытого учебного плана» дошкольной образовательной деятельности, не входящего в рамки непосредственно обучающей программы, пронизывает все время пребывания ребенка в детском саду. Гендерно окрашенный «скрытый учебный план» оказывается действенным механизмом формирования дошкольного «девичества» и стартовых рамок дальнейшей гендерной социализации в школе. Детский сад не только готовит девочку к обучению в школе, он готовит ее быть «девочкой» в школьные годы, усваивать предлагаемые обществом нормы, предписанные школьному возрасту. Анализ дошкольной деятельности и ее интерпретация матерями показывает, что девичья идентичность дошкольницы формируется постоянно - в отдельных играх и небольших практиках ухода, также как в больших мероприятиях, праздничных спектаклях. Однако этот контекст реализации образовательных программ почти не анализируется системно и не учитывается в развитии образовательных программ при их стандартизации.

Глубокая и детальная рефлексия «делания гендера» в детском саду в будущем должна стать основой для разработки методических рекомендаций в федеральных и муниципальных органах управления образованием. Однако следует признать, что текущая ситуация в России пока не может способствовать этому. Интервью с матерями и их описание гендерных практик скорее демонстрирует согласие с деятельностью воспитателей, доверие процессу формирования гендерных стереотипов и норм при организации игр и утренников в детском саду. На данный момент следует отметить, что зарождающийся гражданский потенциал родительской общественности не включает гендерные аспекты воспитания детей.

Важно иметь в виду некоторые методические ограничения данного исследования. Исходя из особенностей работы, мы выбрали в качестве объекта гендерную идентичность девочек, а не дошкольников обоих полов. Подобного рода сравнительное исследование как девочек, так и мальчиков в дошкольном учреждении было бы более целостным, полнее отражая суть гендерного воспитания в детском саду. Второе ограничение - это целевая группа. Мы опросили только матерей как наиболее вовлеченных родителей в практики дошкольного образования их детей. Взгляд отцов не менее важен. И наконец, это исследование предполагало только родительский взгляд, но общение с воспитателями и сотрудниками детского сада, возможно, уточнило бы выводы о развитии тех или иных практик обучения и ухода за детьми в детском саду. 
Мы предполагаем, что проведенное исследование может стать отправной точкой для дальнейшего изучения этой проблематики.

\section{Выражения признательности}

Статья основана на Выпускной квалификационной работе по программе «Социология» НИУ ВШЭ, ставшей призером конкурса выпускных работ по социологии детства, проводимого Исследовательским комитетом по социологии детства Российского общества социологов.

\section{Список источников}

Асонова Е. (2010) Новые ценности в детско-родительских отношениях. Pro et Contra, 1-2 (14): 78-93.

Бем С. (2004) Линзы гендера. Трансформация взглядов на проблему неравенства полов. М.: РОССПЭН.

Гурко Т.А. (2008) Брак и родительство в России. М.: Институт социологии РАН.

Гусева Ю.Е. (2016) Образовательные программы гендерной и псевдогендерной направленности: поддержка разнообразия и однообразия детства. Детский сад: теория и практика, (4): 102-110.

Лорбер Д. (1994) Пол как социальная категория. THESIS, (6): 127-136.

Майорова-Щеглова С.Н. (2014) Трансформации детства в начале XXI в.: к уточнению концепции социального конструирования детства. Вестник РГГУ. Серия: Философия. Сочиология. Искусствоведение, 4 (126): 173-183.

Майофис М., Кукулин И. (2010) Новое родительство и его политические аспекты. Pro et Contra, 1-2 (14): 6-19.

Перегудина В.А. (2013) Возрастные модели гендерной идентичности. Известия ТулГУ. Гуманитарные науки. Bып. 1. Тула: Изд-во ТулГУ.

Савинская О.Б. (2014) Значимость услуг детского сада как социального института. Moниторинг общественного мнения: экономические и сочиальные перемены, (5): 165-173.

Савинская О.Б. (2015) «Образовательное пространство детского сада»: концептуализация понятия и методика конструирования его измерений. ИНТЕРакция. ИНТЕРвъю. ИНТЕРпретация, (9): 30-42.

Савинская О. Б. (2016) Гендерное равенство в STEM-программах дошкольного образования как фактор успешного технологического развития России. Женщцина в российском обществе, 3 (80): 16-24.

Старостина Ю.А. (2017) Феномен форсирования развития дошкольников в современной российской семье. Диссертация на соискание ученой степени кандидата психологических наук. М.: МГУ. 
Штылева Л.В. (2001) Методические аспекты гендерной экспертизы образовательных программ и пособий. Гендерный подход в дошкольной педагогике: теория и практика, (2): 70-73.

Эриксон Э. (1996) Детство и общество. СПб.: Университетская книга.

Ярская-Смирнова Е.Р. (2000) Гендерное неравенство в образовании: понятие скрытого учебного плана. Гендерные исследования, (5): 295-301.

Goffman E. (1976) Gender Ddisplay. Studies in the Anthropology of Visual Communication, (3): 69-77.

Heckman J. J. (2006) Skill Formation and the Economic of Investing in Disadvantaged Children. Science, 312 (6): 1900-1902.

Jackson Ph. W. (1968) Life in Classrooms. New York: Holt, Rinehart and Winston.

James A., Jenks Ch., Prout A. (1998) Theorizing Childhood. Cambridge: Polity Press.

Lofland J., Lofland L. (1995) Analyzing Social Settings: A Guide to Qualitative Observation and Analysis. 3rd ed. Belmont, CA: Wadsworth.

Reay D. (1998) Class Work: Mothers' Involvement in Children's Schooling. London: University College Press.

Schmidt M., Tomasello M. (2012) Young Children Enforce Social Norms. Current Directions in Psychological Science, 21 (4): 232-236. 
Anastasia Cheredeeva, Olga Savinskaya

\title{
GENDER (IN)EQUALITY IN THE KINDERGARTEN: MOTHER'S NARRATIVES ON HIDDEN CURRICULUM AND GIRL'S IDENTITY
}

\begin{abstract}
The article explores the pre-school girlhood as a culture which effects on construction of gender identity. It is based on the example of studying the maternal reflection of preschool education of girls in kindergarten. The empirical base of the research contains 11 interviews with mothers of girls at preschool age and 4 dyadic interviews (with both mothers and daughters aged 4-7) gathered in spring 2016. One of the goals of the study is to detect the elements of 'hidden curriculum' - the latent system of norms, which implicitly broadcast gender standards. Analysis of the variety of practices and aspects of kindergarten (educational programs, after-dinner sleeping, game playing, communication etc.) shows that 'hidden curriculum' permeates the entire daily routine of preschool-aged children. Analysis of the collected interviews shows that mothers support the gender order of the child's education and care in kindergarten, putting forward their arguments of consent and justification of the educational practices embodied in the kindergarten routine. Cooperating with kindergarten's teachers, they producing a 'hidden curriculum' that imposes the traditional model of femininity; this creates socialization practices that set a narrow framework for the construction of girl gender identity, depriving girls of the opportunity to follow the individual educational trajectory and to develop their own unique personality. The gendered 'hidden curriculum' proves to be an effective mechanism for both formation of the preschool girlhood and the starting framework for further gender socialization at school. As a matter of fact, the kindergarten prepares girl not only to learn in school but to be a good 'schoolgirl', which is assume the assimilation the social-determined norms prescribed for appropriate girls behavior and attitudes.
\end{abstract}

Keywords: interviewing, schoolgirls, gender identity, hidden curriculum, mothering, gender expertise of preschool education

DOI: $10.17323 / 727-0634-2018-16-3-441-456$

\section{References}

Asonova Y. (2010) Novyye tsennosti v detsko-roditel'skih otnosheniyah [New Values in Child-Parent Relations]. Pro et Contra, 14 (1-2): 78-93.

Anastasia Cheredeeva - graduated student at Social Sciences Faculty, National Research University 'Higher School of Economics', Moscow, Russian Federation. Email: cheredeeva.a@gmail.com

Olga Savinskaya - candidate of sociological sciences, associate professor, Department of Sociology of the National Research University 'Higher School of Economics', Moscow, Russian Federation. Email: osavinskaya@hse.ru 
Bem S. (2004) Linzy gendera: Transformatsiia vzgliadov na problemu neravenstva polov [The Lenses of Gender. Transforming the Debate on Sexual Inequality]. Moscow: ROSSPEN.

Ericson E. (1996) Detstvo i obschestvo [Childhood and Society]. St. Petersburg: Universitetskaya kniga.

Goffman E. (1976) Gender Display. Studies in the Anthropology of Visual Communication, (3): 69-77.

Gurko T. A. (2008) Brak i roditel'stvo v Rossii [Marriage and Parenthood in Russia]. Moscow: Institut Sociologii RAN.

Guseva Yu.E. (2016) Obrazovatel'nye programmy gendernoy i psevdogendernoy napravlennosti: podderzhka raznoobraziya i odnoobraziya detstva [Educational Programs of Gender and Pseudo-gender Orientation]. Detskiy sad: teoriya i praktika [Kindergarten: Theory and Practice], 64 (4): 102-110.

Heckman, J.J. (2006) Skill Formation and the Economics of Investing in Disadvantaged Children. Science, 312 (6): 1900-1902.

Iarskaia-Smirnova E.R. (2000) Gendernoye ravenstvo v obrazovanii: ponyatie skrytogo uchebnogo plana [Gender Equality in Education: The Conception of Hidden Curriculum]. Gendernye issledovania [Gender Studies], (5): 295-301.

Jackson Ph.W. (1968) Life in Classrooms. New York: Holt, Rinehart and Winston.

James A., Jenks Ch., Prout A. (1998) Theorizing Childhood. Cambridge: Polity Press.

Lofland J., Lofland L. (1995) Analyzing Social Settings: A Guide to Qualitative Observation and Analysis. Belmont, CA: Wadsworth.

Lorber J. (1994) Pol kak sotsial'naya kategoriya [Gender as a Social Category]. THESIS, (6): $126-137$.

Mayofis M., Kukulin I. (2010) Novoye roditel'stvo I yego politicheskiye aspekty [New Parenting and its Political Aspects]. Pro et Contra, 1-2 (14): 6-19.

Mayorova-Shcheglova S.N. (2014) Transformatsii detstva v nachale XXI v.: k utochneniyu kontseptsii sotsial'nogo konstruirovaniya detstva [Transformation of Childhood in the Early XXI Century: On the way to Define the Conception of Social Construction of Childhood]. Vestnik RGGU. Seriya: Filosofiya. Sotsiologiya. Iskusstvovedenie [Review of RSUH. Series: Philosophy, Sociology, History of Art], 126 (4): 173-183.

Peregudina V.A. (2013) Vozrastnye modeli gendernoy identichnisti [The Age Models of Gender Identity]. Izvestiya TulGU. Gumanitarnye nauki [The News of TulGU. Gumanities]. Vol.1. Tula: TulGU.

Reay D. (1998) Class Work: Mothers' Involvement in Children's Schooling. London: University College Press.

Savinskaya O.B. (2014) Znachimost' detskogo sada kak sotcial'nogo instituta [The Importance of Kindergarten as a Social Institute]. Monitoring obschestvennogo mnenia: ekonomicheskiye i sotsial'nye peremeny [The Monitoring of Public Opinion: Economic and Social Changes], 123 (5): 165-173. 
Savinskaya O. B. (2015) 'Obrazovatel'noe prostranstvo detskogo sada': kontseptualizatsiya ponyatiya i metodika konstruirovaniya ego izmereniy ['Educational Space of a Kindergarten': Conceptualization of a Concept and a Technique for Constructing its Dimensions]. INTERaktsiya. INTERv'yu. INTERpretatsiya [Interaction, Interview, Interpretation], (9): 30-42.

Savinskaya O.B. (2016) Gendernoe ravenstvo v STEM-programmakh doshkol'nogo obrazovaniya kak faktor uspeshnogo tekhnologicheskogo razvitiya Rossii [Gender Equality in the Early STEM-education as a Factor of Russia's Successful Technological Development]. Zhenshchina s rossiyskom obshchestve [Woman in Russian Society], 80 (3): 16-24.

Schmidt M., Tomasello M. (2012) Young Children Enforce Social Norms. Current Directions in Psychological Science, 21 (4): 232-236.

Shtileva L. V. (2001) Metodicheskie aspekty gendernoy ekspertizy obrazovatel'nykh programm i posobiy [Methodological Aspects of Gender Expertise of Educational Programs and Manuals] Gendernyy podkhod v doshkol'noy pedagogike: teoriya i praktika [Gender Approach in Preschool Pedagogy: Theory and Practice], (2): 70-73. 